\title{
Optimization of solid waste collection circuits
}

\author{
Nezha Haddoun ${ }^{1 *}$ and Driss Khomsi ${ }^{1}$ \\ ${ }^{1}$ Mohammadia School of Engineers, Hydraulic Systems Analysis Laboratory, 10090 Rabat, Morocco
}

\begin{abstract}
The management of solid waste is a significant problem that can negatively affect human health, the environment, and the living environment. One of the biggest threats to sustainable development is environmental pollution due to poor waste management. The "collection" component represents the most expensive link in management and is subject to several constraints. Its optimization will, therefore, make it possible to optimize the overall cost of management. Solving the problem comes down to solving the "Periodic Capacitated Arc Routing Problem" PCARP, an extension of the famous CARP problem over several periods. The objective is to minimize the number of vehicles required and the total cost of collection trips according to the set schedule. This document defines this NP-difficult problem, summarizes the different optimization methods used to solve the problem with a literature review, and discusses the latest studies and results.
\end{abstract}

\section{Introduction}

Solid waste is a threat to the quality of the environment and the living environment. The majority of cities are experiencing strong population growth and beyond that produce increasingly high amounts of solid waste. The increase in the quantities of waste poses a series of problems in terms of collection, disposal, and landfill, especially in small municipalities and urban areas. 60 to $80 \%$ of solid waste management expenses is mainly linked to their pickup and transport, so good optimization of waste collection techniques will decrease the cost of their management and will also lessen pollution of the environment and this by minimizing $\mathrm{CO} 2$ emissions, which will contribute to sustainable development.

This challenging problem belongs to the Vehicle Routing Problems (VRP) and mainly the Arc Routing Problems (ARP). The road network is modeled by a graph comprising arc/edge (street). These must be treated at least once, the goal is to find a cycle (or circuit) of minimum cost crossing at least once through each network link. This problem is called Chinese Postman Problem (CPP). To reflect the real case, we add to this problem the constraint of the "Capacity of the vehicles", we then speak about the CARP "Capacitated Arc Routing Problem."

However, the CARP remains too simplistic to model the real problem of optimizing reliable waste collection circuits. In reality, the collection is done according to a schedule. This planning depends on the region, the size of the city and the type of habitat. Regions

* Corresponding author: haddoun.nezha@gmail.com 
with apartment buildings are characterized by low possibilities for waste storage (underground containers for example) and generally require daily collection. For neighbourhoods with single-family houses, collection is done by periods because these houses generally have a garage with a container allowing waste to be stored for a few days. In addition, there are constraints that may be imposed by municipalities, for example a political will to collect certain areas on a daily basis for reasons of image or hygiene. This adds another constraint to the problem, namely the "Periodicity of collection". We are talking about the famous 'PCARP'. The frequency of collection is generally the same every week for several reasons: (1) Waste production is relatively stable; (2) Keep the same passage days each week to prevent residents from forgetting to take out their containers; (3) Keep trips stable each week to facilitate the work of the crews

"CARP" was initiated by Golden and Wong [1]. The elementary problem relates to undirected graph. The depot includes a set of vehicles whose capacity is known. The edges of a strictly positive demand (quantity of waste to be collected) must be crossed to be served. CARP consists of finding a fleet of vehicle tour of minimum total cost, such as: (1) Each tour, provided by a vehicle, begins and ends at the deposit; (2) Each required edge can be treated several times but must be served only by one tour; (3) The total quantity collected in a trip must not surpass the capacity of the vehicle.

Depending on the constraints to be considered, there are several types of CARP: (1) Undirected CARP (UCARP) for streets treatable in one pass and in any direction[2]. We have also the "Directed CARP', (DCARP), where an arc designates a traffic lane with a clearly defined direction of treatment, and the "Mixed CARP'" (MCARP), which is the most realistic approach, because it combines arcs and edges in a graph.

It can be used to model a situation where some street segments may cross in one direction and others in both directions; (2) Stochastic CARP (SCARP), where the demand or the travel time of vehicles is random and random variables are used to calculate the value of the objective function [3-5]; (3) Multi-depot CARP (M-CARP), where there is a network of $\mathrm{M}$ depots from which a set of vehicles depart, serve the required edges once and end the trip at the same depot[6].

A variant of the M-CARP problem is "CARP with intermediate facilities" (CARPIF), in which vehicles visit several stations to load or unload their contents [7]; (4) CARP with Refill Points (CARP-RP): service vehicles trace the lines on the streets and are recharged at certain network nodes by recharging vehicles. These joins the node of the deposit. It is therefore obligatory to schedule appointments between the two types of vehicles.

A concrete example is the case of waste collection where there are two types of trucks : large trucks which cannot cross all the streets and small trucks which have low capacity. To avoid the return of small trucks to the depot, it is necessary to organize meetings with large trucks that can serve as depots [8-9]; (5) Open CARP (OCARP), introduced by Usberti et al.[10] for applications where there is no depot in the network and it is not necessary to create paths that form a cycle. Vehicles can begin and finish their tour at different nodes in the graph; (6) CARP with Time Windows (CARPTW), with time constraints to start and end the service on each of the arcs [11-13]. A similar problem has been addressed by Tagmouti et al. [14-17], where there is a penalty in the total cost if the service starts earlier or later than the desired time; (7) Periodic CARP (PCARP) is the problem where the road segments require a service frequency and must be visited once or more during a time horizon.

As mentioned above, the "PCARP" version is the most suitable for studying the problem of solid waste collection. "PCARP" was introduced by Lacomme et al.[18]. The basic PCARP is relative to an non oriented graph $G$ and concerns several periods "p periods". The depot contains $\mathrm{V}$ identical vehicles of defined capacity $\mathrm{W}$. The number of vehicles is an unknown to be determined. Each link $[\mathrm{i}, \mathrm{j}]$ has a crossing price $\mathrm{c}_{\mathrm{ij}}$, a 
collection frequency $f_{i j}$ and a set of combinations of collection days comb (i, j). The demand $d_{i j}$ to be processed for any combination $k € \operatorname{comb}(i, j)$ and for any period $p$ is known. And like CARP, the demand must not surpass the capacity. The objective is to find out an arrangement of days for each task and a set of tours relative to each day optimizing the total cost with the respect of the constraints below: (1) Each action [i, j] is served $f_{i j}$ times on the horizon, but at most once a day; (2) Each trip begin and finish at the depot; (3) A task relating to a day is served by a single tour in that day; (4) The capacity of the vehicle is respected. This document is structured as following: In section 2, the different resolution methods of the problem are exposed as well as a literature review. In section3, the latest results are presented with a discussion and a comparison.

\section{Method}

"CARP', is an NP-difficult problem. Its resolution is based on exact methods, heuristics and metaheuristics:

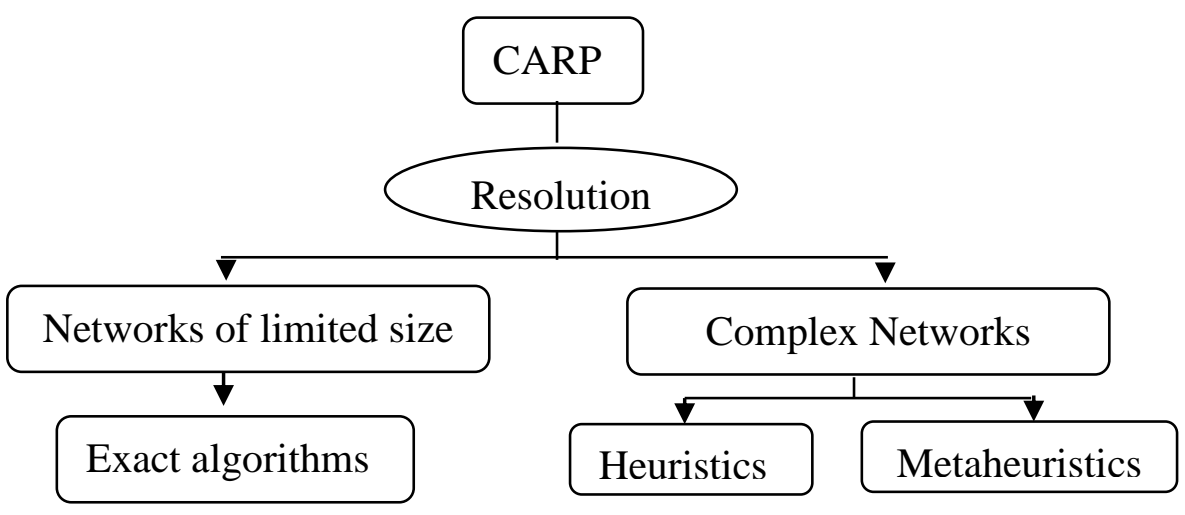

Fig. 1. CARP Resolution methods

The exact algorithms proposed to solve the CARP [1][9][19-24]. These methods have only been able to solve problems of very limited size (networks of 200 nodes and 300 edges for the method proposed by Martinelli et al. (2013)). However, heuristics were proposed. They make it possible to give good quality solutions, without guarantee of optimality, but for the benefit of a reduced computation time : 'Construct-Strike', by Christofides (1973), "'Augment-Merge"' by Golden and Wong (1981), "'Path-Scanning', by Golden et al.(1983), 'Parallel-Insert', by Chapleau et al.(1984), 'Route First-Cluster Second' by Ulusoy (1985), 'Cluster First-Route Second'’ by Benavent et al. (1990).

These heuristics constitute a starting point (give an initial solution) for metaheuristics that can be seen as powerful and advanced heuristics insofar as they are generalizable to several optimization problems. Among the metaheuristics published for CARP, we find: (1) Taboo Search (TS): method introduced mainly by Glover (1986), Hansen (1986), Glover and Laguna (1997). Adoped to CARP by Hertz et al. [25-26] (algorithm tested on instances of around 250 vertices and 375 edges); (2) Simulated Annealing Algorithm (SA): The first who applied this method to CARP is Li (1992), which is the first metaheuristic proposed for CARP. Also, Tirkolaee et al. [27- 29] solved the problem through heuristics to generate initial solutions which were improved by the (SA) algorithm; (3) Genetic Algorithms (GA): bio-inspired method introduced by Holland (1975) as part of an analogy with natural selection of species. It was then adapted by Goldberg (1989) to be used to the resolution of 
optimization problems. To solve the CARP, the first genetic algorithm was formulated by Lacomme et al [30]. In 2002, this algorithm was extended to solve ECARP (Extended CARP), SCARP (Stochastic CARP) and PCARP (Periodic CARP) by W.R.Cherif [31]. In 2018, a hybrid genetic algorithm was proposed by Arakaki et al. [32] to solve the OCARP; (4) Ant Colony Optimization (ACO): In 2003, Lacomme et al. [33] formulated the first algorithm for CARP. Then this method was developed to solve the different types of CARP [34-37]. In 2018, Tirkaloee et al. [38] were interested in the multi trip CARP by proposing a hybrid augmented (ACO) algorithm based on an improved max - min ant system with an innovative probability function and a simulated annealing algorithm.

"PCARP" is also a NP-hard problem, its resolution was mainly based on metaheuristics combined with heuristics: A memetic algorithm was presented in Lacomme et al [19] and later detailed in Lacomme et al [39] to address the problem of waste collection. Memetic algorithms are a form of evolutionary algorithms that combine genetic algorithms with local search in mutation. This algorithm uses elements similar to that proposed by Lacomme et al. (2001) for CARP. The goal is to reduce the total cost of trips. The combinations of days for each task are set according to their frequency. This allows the Route first-cluster second algorithm to evaluate a sequence of tasks per period (day). We find the best combination for each of the days, and finally, we combine the solutions found for each period of the horizon to solve the problem.

In 2003, Chu et al. [40] have developed two lower limits for PCARP. In 2005, they proposed the first full linear program to solve small problems. They also developed two insertion heuristics and a two-phase heuristic to solve larger problems [41]. The insertion heuristic gives results in a shorter time, but the two-phase method generates better results.

A greedy heuristic and scatter search was proposed in 2006 by Chu et al. [42]. the scatter search shows its ability to improve the initial solutions and surpasses the greedy heuristic. Kansou et al. (2009) [34] solved the problem by combining an (ACO) algorithm to optimize the order of tasks and a heuristic for the insertion of tasks in the case of a mixed network. The results indicate that the proposed approach outperforms existing algorithms. A comparison with the best memetic methods demonstrated the robustness, speed, and performance of this method.

In 2011, Mei et al. [43] have developed a new Memetic Algorithm (MA) to solve PCARP. They developed a "Route-Merging" (RM) operator to optimize the number of vehicles. The MA with RM (MARM) was compared to existing meta-heuristic algorithms. The experimental results show that this method obtained better results in much less time.

In 2017, a new Route Decomposition operator (RD) was detailed by Zhang et al. [44] to improve the number of vehicles and the total cost simultaneously. Then, (RD) is combined into the Memetic Algorithm (MA) for the PCARP. The MA with RD (MARD) was calculated and compared to the most recent methods. The experimental results show that MARD gives good results. This method becomes more interesting especially when the size of problem increases.

In 2017, Chen et al. [45] proposed an efficient two-phase Hybrid Local Search algorithm (HLS). The first phase is designed to optimize the main objective: the number of vehicles. In contrast, the second phase seeks to optimize further the two objectives: the number of vehicles and total cost using the number of vehicles resulting from the first phase as the upper limit to delimit the search space. This method gave good results about the quality of the solution and computing time.

In 2018, Tirkolaee et al. developed a robust model for PCARP [28]. The problem is solved through a hybrid algorithme (heuristic algorithme and (SA) algorithme). In 2019, Tirkolaee et al. [46] treated PCARP with demand uncertainty.

In 2020, Bilal Kanso [47] applied an (ACO) algorithm followed by a simulated annealing local search method to solve the 'Multi Depot Periodic Open Capacited Arc 
Routing Problem" (MDPOCARP). The initial solution was calculated through a constructive heuristic "Nearest Insertion Heuristic"' (NIH). This method allows obtaining very efficient results.

\section{Results and discussion}

The problem of optimizing reliable waste collection circuits was studied mainly by Lacomme et al. and Tirkolaee et al. They proposed solutions based on different optimization methods and taking into account several other real constraints in addition to 'Capacity"' and 'Periodicity'.

In 2002, Lacomme et al. [18] have modeled the problem with an extended PCARP to also deal with the case of mixed networks, the objective being to minimize the function $\mathrm{F}$ (nvu, cost) with nvu: several vehicles used. To solve the problem, a robust genetic algorithm was proposed. It was compared to four heuristics that have demonstrated their ability to minimize bi-objective functions: Best Insertion Heuristic (BIH), Daily Genetic Algorithm (DGA), Periodic Genetic Algorithm (PGA), and Improved Genetic Algorithm (IGA).

Table 1. Comparison of BIH, DGA, PGA and IGA on 23 PCARP instances (Lacomme et al. [18]).

\begin{tabular}{|c|c|c|c|c|}
\hline AVERAGE VALUE & BIH & DGA & PGA & IGA \\
\hline Fleet size $n v u$ & 7.00 & 4.04 & 3.65 & 3.56 \\
\hline Cost of trips cost & 968.4 & 689.7 & 706.3 & 688.9 \\
\hline CPU time per instance (min) & $<1 \mathrm{~s}$ & 4.63 & 1.09 & 2.12 \\
\hline
\end{tabular}

The results show that PGA is better than DGA in-vehicle optimization, even though the total cost of tours is more significant. Also, IGA gives the best results: better optimization of vehicles and total cost.

In 2016, to solve the concrete waste problem, Tirkolaee et al. [27] proposed a new representation for the CARP problem to which they associated a new constraint: uncertain demand at the edges. The aim is to minimize the distance traveled. As a solution, a heuristic algorithm is developed to give initial solutions then a (SA) algorithm is used to improve these solutions. The results indicated that the performances of this method are correct (significant gain in computing time) by comparing with the exact method (CPLEX solver):

Table 2. Comparing results of SA and CPLEX for robust problem with $\mathrm{d}^{\wedge}=0.05 \mathrm{~d}$ (Tirkolaee et al. [27]) 


\begin{tabular}{|c|c|c|c|c|c|}
\hline \multirow{2}{*}{ P } & \multicolumn{2}{|c|}{ CPLEX } & \multicolumn{3}{c|}{ SA } \\
\cline { 2 - 6 } & $\begin{array}{c}\text { Objective } \\
\text { function }\end{array}$ & $\begin{array}{c}\text { Run time } \\
(\mathrm{sec})\end{array}$ & $\begin{array}{c}\text { Objective } \\
\text { function }\end{array}$ & $\begin{array}{c}\text { Run time } \\
(\mathrm{sec})\end{array}$ & $\begin{array}{c}\text { GAP } \\
(\%)\end{array}$ \\
\hline P1 & 998 & 40.4 & 1016 & 8.5 & 1.8 \\
\hline P2 & 1121 & 92.0 & 1154 & 15.32 & 2.92 \\
\hline P3 & 1815 & 183.5 & 1865 & 18.95 & 2.73 \\
\hline P4 & 2689 & 224.1 & 2743 & 26.22 & 2.01 \\
\hline P5 & 3550 & 382.6 & 3644 & 34.64 & 2.65 \\
\hline P6 & 4144 & 686.2 & 4211 & 42.96 & 1.61 \\
\hline P7 & 5318 & 956.6 & 5428 & 51.13 & 2.06 \\
\hline P5 & 6180 & 1825.3 & 6286 & 6023 & 1.72 \\
\hline P9 & 6756 & 3014.5 & 6845 & 68.17 & 1.31 \\
\hline P10 & 7423 & 3600 & 7583 & 77.42 & 2.16 \\
\hline Ave & 3999.4 & 1100.52 & 4077 & 40.36 & 2.10 \\
\hline
\end{tabular}

With $\quad \mathrm{d}^{\wedge}=\delta \mathrm{d}, \delta$ : deviation level, $\mathrm{d}$ : demand

In 2018, Tirkolaee et al. [28] is interested to a more general model considering several real constraints: Vehicle capacity, periodicity, multiple trips, the uncertainty of demand, and team working time. The goal is to optimize number of vehicles and the optimal tour for each vehicle. Vehicles at the depot, start their trips to serve the edges having a demand and then join to the depot. The capacity constraint and the maximum available time allow to have the number of vehicles required. The working time of the team indicates the maximum time available for each vehicle considered. As a solution, a hybrid algorithm was proposed based on a heuristic algorithm to have initial solutions (200 solutions) and a (SA) algorithm to improve these solutions. This method has given good results:

Table 3. Comparing results of SA and CPLEX for robust problem with $\mathrm{d}^{\wedge}=0.05 \mathrm{~d}$ (Tirkolaee et al. [28])

\begin{tabular}{|c|c|c|c|c|c|}
\hline \multirow{2}{*}{ P } & \multicolumn{2}{|c|}{ CPLEX } & \multicolumn{3}{c|}{ SA } \\
\cline { 2 - 6 } & $\begin{array}{c}\text { Objective } \\
\text { function }\end{array}$ & $\begin{array}{c}\text { Run time } \\
(\mathrm{sec})\end{array}$ & $\begin{array}{c}\text { Objective } \\
\text { function }\end{array}$ & $\begin{array}{c}\text { Run time } \\
(\mathrm{sec})\end{array}$ & $\begin{array}{c}\text { GAP } \\
(\%)\end{array}$ \\
\hline P1 & 740.93 & 86.94 & 757.59 & 11.61 & 2.25 \\
\hline P2 & 919.5 & 173.74 & 928.03 & 23.99 & 0.93 \\
\hline P3 & 1406.74 & 600.54 & 1441.65 & 30.27 & 2.48 \\
\hline P4 & 2161.53 & 856.23 & 2214.27 & 31.53 & 2.44 \\
\hline P5 & 2739.57 & 1379.17 & 2798.96 & 48.35 & 2.17 \\
\hline P6 & 2998.99 & 2015.8 & 3061.44 & 50.8 & 2.08 \\
\hline P7 & 3919.52 & 3209.14 & 3978.27 & 69.54 & 1.5 \\
\hline P8 & 4826.8 & 3600 & 4938.75 & 96.39 & 2.32 \\
\hline P9 & $-*$ & 3600 & 5884.43 & 117.93 & - \\
\hline P10 & - & 3600 & 6888.68 & 191.58 & - \\
\hline
\end{tabular}

${ }^{8}$ No solution found

In 2018, Tirkolaee et al. [38] studied the multi-trip CARP assuming that depositts and disposal facilities were deposited in different locations. Using the Taguchi parameter design method, a hybrid algorithm is formulated supported by an improved Max-Min Ant System (IMMAS) to solve medium and large problems. The results show the effectiveness of the method used by comparing it with the methods: Max-Min Ant System MMAS developed by shuttle and Hoos [48] by changing the AS algorithm and Initial Solution Heuristic Algorithm ISHA: 


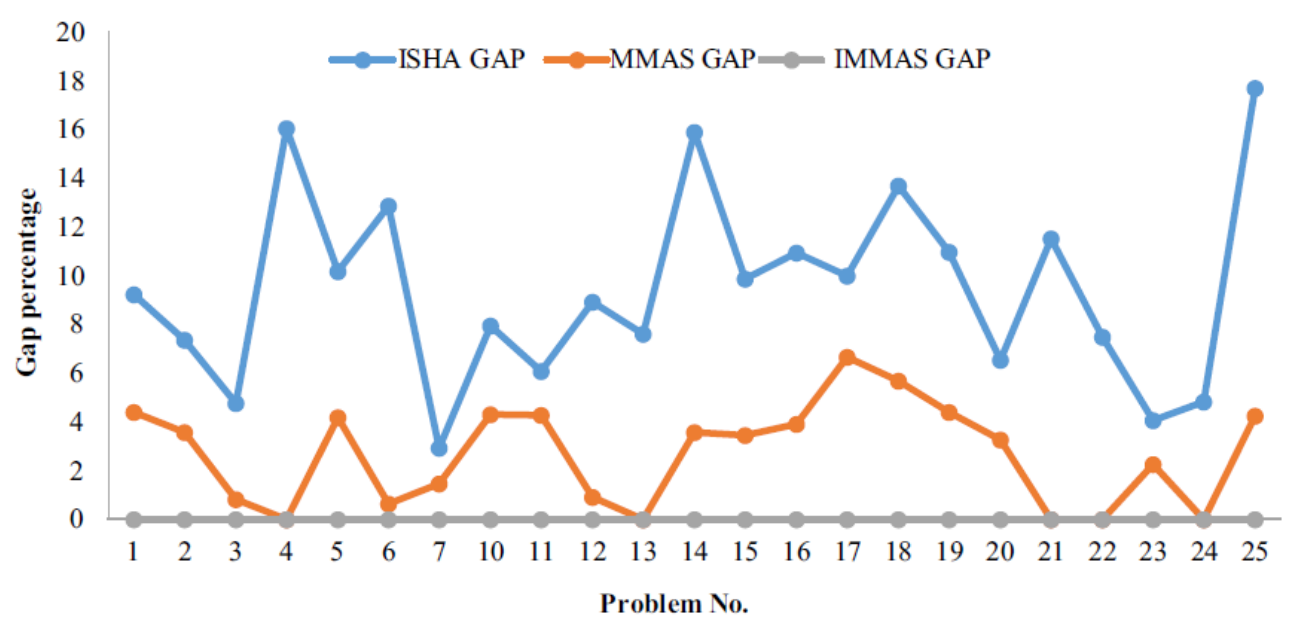

Fig. 2. Comparison of gaps computed between the proposed algorithms for the large sized instance problems (Tirkolaee et al. [38])

In 2019, Tirkolaee et al. [29] considered the following constraints to model the solid waste collection problem: time window and multiple trips, assuming that the waste is deposited at the nodes. Therefore, the problem comes down to resolve a VRP: "multi-trip vehicle routing problem with time windows." A simulated annealing algorithm was developed, and its results show that it gives excellent performance in a reduced computation time:

Table 4. Computational results (Tirkolaee et al. [29])

\begin{tabular}{|l|l|l|l|l|l|l|l|}
\hline Problem & $\begin{array}{l}\text { Number } \\
\text { of used } \\
\text { vehicles }\end{array}$ & $\begin{array}{l}\text { CPLEX } \\
\text { objective } \\
\text { value }\end{array}$ & $\begin{array}{l}\text { CPLEX } \\
\text { run time } \\
\text { (sec) }\end{array}$ & $\begin{array}{l}\text { SA mean } \\
\text { objective } \\
\text { value }\end{array}$ & $\begin{array}{l}\text { SA mean } \\
\text { run time } \\
\text { (sec) }\end{array}$ & $\begin{array}{l}\text { SA best } \\
\text { objective } \\
\text { value }\end{array}$ & GAP(\%) \\
\hline P1 & 1 & 2862 & 20.15 & 2891.5 & 2.67 & 2873 & 0.38 \\
\hline P2 & 1 & 3023 & 79.64 & 3115.1 & 4.52 & 3046 & 0.76 \\
\hline P3 & 2 & 3716 & 218.25 & 3783.2 & 7.9 & 3751 & 0.93 \\
\hline P4 & 2 & 4232 & 361.14 & 4338.6 & 11.29 & 4322 & 2.08 \\
\hline P5 & 2 & 4571 & 1001.54 & 4664.3 & 13.82 & 4613 & 0.91 \\
\hline P6 & 3 & 5408 & 1825.8 & 5492.4 & 17.18 & 5478 & 1.28 \\
\hline P7 & 4 & 5644 & 2438.71 & 5703.02 & 23.14 & 5694 & 0.88 \\
\hline P8 & 4 & 6469 & 3714.92 & 6534.48 & 28.22 & 6517 & 0.74 \\
\hline P9 & 5 & - & - & 7288.68 & 32.86 & 7260 & - \\
\hline P10 & 5 & - & - & 7404.16 & 37.04 & 7392 & - \\
\hline P11 & 6 & - & - & 8179.12 & 44.15 & 8165 & - \\
\hline P12 & 7 & - & - & 9376.83 & 56.73 & 9328 & - \\
\hline P13 & 7 & - & - & 9613.21 & 61.28 & 9582 & - \\
\hline P14 & 8 & - & - & 10328.9 & 69.19 & 10240 & - \\
\hline P15 & 8 & - & - & 10864.57 & 76.84 & 10816 & - \\
\hline
\end{tabular}

In 2019, Tirkolaee et al. [46] solved PCARP with uncertain demand. Goals are to optimize the total cost (i.e., the costs of moving and using the vehicles) and optimize the vehicles longest distance. The $\varepsilon$-constraint method is executed, then, a multi-objective invasive weed optimization algorithm is formulateded. The Taguchi design method allowed to optimize its parameters. This method is able to give good results for both small and large problem: 
Table 5. Summary of the various studies carried out to solve the problem of optimizing sold waste collection circuits

\begin{tabular}{|c|c|c|c|c|c|}
\hline & $\begin{array}{c}\text { Considered } \\
\text { constraint }\end{array}$ & Modelization & $\begin{array}{c}\text { Optimization } \\
\text { method }\end{array}$ & Objective & Result \\
\hline $\begin{array}{l}\text { Lacomme } \\
\text { et al. } \\
2002\end{array}$ & $\begin{array}{l}\text { - Periodicity } \\
\text { - Mixed graph }\end{array}$ & $\begin{array}{l}\text { Extended } \\
\text { PCARP }\end{array}$ & $\begin{array}{l}\text { Powerful } \\
\text { Genetic } \\
\text { Algorithm }\end{array}$ & $\begin{array}{l}\text { To minimize } \\
\text { number of } \\
\text { vehicle }+ \\
\text { total cost }\end{array}$ & $\begin{array}{l}\text { Good results } \\
\text { compared to } \\
4 \text { heuristics }\end{array}$ \\
\hline $\begin{array}{l}\text { Tirkolaee } \\
\text { et al. } \\
2016 .\end{array}$ & $\begin{array}{l}\text { Uncertainty of } \\
\text { demand }\end{array}$ & CARP & $\begin{array}{l}\text { (SA) } \\
\text { algorithm + a } \\
\text { heuristic } \\
\text { algorithm }\end{array}$ & $\begin{array}{l}\text { To optimize } \\
\text { the total cost }\end{array}$ & $\begin{array}{l}\text { Reduced } \\
\text { computing } \\
\text { time }\end{array}$ \\
\hline $\begin{array}{l}\text { Tirkolaee } \\
\text { et al. } \\
2018\end{array}$ & $\begin{array}{l}\text { Multi-trip depots } \\
\text { and } \\
\text { disposal are } \\
\text { separated }\end{array}$ & CARP & $\begin{array}{l}\text { New algorithm } \\
\text { based on an } \\
\text { Improved } \\
\text { Max-Min } \\
\text { Ant System }\end{array}$ & $\begin{array}{l}\text { To minimize } \\
\text { the total cost }\end{array}$ & $\begin{array}{l}\text { Good results } \\
\text { compared to } \\
\text { MMAS } \\
\text { method } \\
\text { and ISHA } \\
\text { method }\end{array}$ \\
\hline $\begin{array}{l}\text { Tirkolaee } \\
\text { et al. } \\
2018\end{array}$ & $\begin{array}{l}\text { - Periodicity } \\
\text { - Multi trip } \\
\text { - Uncertainty of } \\
\text { demand } \\
\text { - Time window }\end{array}$ & PCARP & $\begin{array}{l}(\mathrm{SA}) \\
\text { algorithm + a } \\
\text { heuristic } \\
\text { algorithm }\end{array}$ & $\begin{array}{l}\text { To minimize } \\
\text { number of } \\
\text { vehicles + } \\
\text { optimal trip } \\
\text { for each } \\
\text { vehicle }\end{array}$ & Good results \\
\hline $\begin{array}{l}\text { Tirkolaee } \\
\text { et al. } \\
2019\end{array}$ & $\begin{array}{l}\text { - Muti trip } \\
\text { - Time window }\end{array}$ & VRP & $\begin{array}{l}\text { Efficient SA } \\
\text { Algorithm }\end{array}$ & $\begin{array}{l}\text { To minimize } \\
\text { total cost }\end{array}$ & $\begin{array}{l}\text { Great } \\
\text { performance } \\
\text { in a } \\
\text { short } \\
\text { time }\end{array}$ \\
\hline
\end{tabular}

\section{Conclusion}

The issue of optimizing waste management is relatively recent but has already given rise to numerous studies. PCARP remains the most proper application to solve this famous problem. To translate reality, we associate several constraints with it: time window, the uncertainty of demand, multiple trips, graphs orientation. According to the analysis made on the various works dealing with this problem, we notice that the most general study (robust model), which considers the maximum of constraints, comes from Tirkolaee et al. (2018).

The solutions show the power of this method in terms of optimization of the objective function and the calculation time. However, this method persists restricted because it is valid only for undirected graphs. This "mixed graph" constraint was taken into account by the study carried out by Lacomme et al. (2002), who looked at the extended PCARP to solve the solid waste problem. Therefore, we deduce that there are still efforts to be made: include as many constraints as possible to approach reality and use the new optimization methods to deal with large-scale problems (genetic algorithm, ant colony algorithm, or particle swarms example). 
In the future, we intend to develop further the robust model of Tirkolaee et al. (2018) to be interested in mixed graphs. Besides, solving the problem with a metaheuristic other than (SA) algorithm could be more interesting, because the latter is based on the choice of several parameters taken empirically.

\section{References}

1. B.L. Golden, R.T. Wong, Capacitated arc routing problems, Netw. 11, 3, 305-315 (1981) https://doi.org/10.1002/net.3230110308

2. A. Hertz, M. Mittaz, A Variable Neighborhood Descent Algorithm for the Undirected Capacitated Arc Routing Problem, Transp. Sci. 35, 4 (2001) https://doi.org/10.1287/trsc.35.4.425.10431

3. G. Fleury, P. Lacomme, C. Prins, Evolutionary algorithms for stochastic arc routing problems, in Ap. of Evo. Comp, 501-512 (2004)

4. G. Laporte, R. Musmanno, F. Vocaturo, An adaptive large neighbourhood search heuristic for the capacitated arc-routing problem with stochastic demands, Transp. Sci. 44, 1, 125-135 (2010) https://www.jstor.org/stable/25769483

5. S.G. Martin, A.A. Juan, D. Riera, M.G. Elizondo, J.J. Ramos, A simheuristic algorithm for solving the arc routing problem with stochastic demands, J. of Sim. 12, 1, 53-66 (2018) https://doi.org/10.1057/jos.2016.11

6. A Amberg, W Domschke, S Voß, Multiple center capacitated arc routing problems: A tabu search algorithm using capacitated trees, in Euro. J. of Oper, 124, 2, 360-376 (2000), https://doi.org/10.1016/S0377-2217(99)00170-8

7. G. Ghiani, G. Improta, G. Laporte, The capacitated arc routing problem with intermediate facilities, Net. 37, 3, 1134-143 (2001) https://doi.org/10.1002/net.3

8. A.D. Pia, C. Filippi, A variable neighborhood descent algorithm for a real waste collection problem with mobile depots, Inter. Trans. in Oper. Res. 13, 2, 125-141 (2006) https://doi.org/10.1111/j.1475-3995.2006.0053

9. A. Amaya, A. Langevin, M. Trépanier, The capacitated arc routing problem with refill points, Oper. Res. Lett. 35, 1, 45-53 (2007) https://doi.org/10.1016/j.orl.2005.12.009

10. F.L. Usberti, PM França, ALM França, The open capacitated arc routing problem, in Comp. \&Oper. Res, 38, 11, 1543-1555 (2011) https://doi.org/10.1016/j.cor.2011.01.012

11. P.A. Mullaseril, Capacitated rural postman problem with time windows and split delivery (1997)

12. B. Kim, S. Kim, and S. Sahoo, Waste collection vehicle routing problem with time windows, Comp. Oper. Res, 33, 12, 3624-3642 (2006) https://doi.org/10.1016/j.cor.2005.02.045

13. C.Ciancio, D. Laganá, F. Vocaturo, Branch-price-and-cut for the Mixed Capacitated General Routing Problem with Time Windows, Euro. J. of Oper. Res. 267, 1, 187-199 (2018) https://doi.org/10.1016/j.ejor.2017.11.039

14. M. Tagmouti, M. Gendreau, J.Y. Potvin, Arc routing problems with time-dependent service costs, Euro. J. of Oper. Res, 181, 1, 30-3916 (2007) https://doi.org/10.1016/j.ejor.2006.06.02

15. M.Tagmouti, Étude d'un problème de tournées de véhicules sur les arcs avec contraintes de capacité et coûts de service dépendants du temps (2008) http://hdl.handle.net/1866/6446

16. M. Tagmouti, M. Gendreau, J.Y. Potvin, A variable neighborhood descent heuristic for arc routing problems with time-dependent service costs, Comp. \& Ind. Eng, 59, 4, 954963 (2010) https://doi.org/10.1016/j.cie.2010.09.006 
17. M. Tagmouti, M. Gendreau, J.Y. Potvin, A dynamic capacitated arc routing problem with time-dependent service costs, Transp. Res. Part C: Emerg. Tech. 19, 1, 20-28 (2011) https://doi.org/10.1016/j.trc.2010.02.003

18. P. Lacomme, C. Prins, W.R. Cherif, Evolutionary algorithms for multiperiod arc routing problems, 9 th Int. Conf. on Inf. Proc. and Manag. of Uncertainty in Knowledge-Based Systems (2002)

19. Hirabayashi, Nishida, Saruwatari, Tour construction algorithm for the capacitated arc routing problem, (1992)

20. R. Baldacci, V. Maniezzo, Exact methods based on node routing formulations for undirected arc routing problems, Netw. 47, 1, 52-60 (2006) https://doi.org/10.1002/net.20091

21. H. Longo, M.P. Aragão, E. Uchoa, Solving capacitated arc routing problems using a transformation to the CVRP, Comp. \& Oper. Res, 33, 6, 1823-1837 (2006) https://doi.org/10.1016/j.cor.2004.11.020

22. E. Bartolini, J.F. Cordeau, G. Laporte, Improved lower bounds and exact algorithm for the capacitated arc routing problem, Math. Prog, 137, 1-2, 409-452 (2013) https://doi.org/10.1007/s10107-011-0497-4

23. E. Bartolini, J.F. Cordeau, G. Laporte, An Exact Algorithm for the Capacitated Arc Routing Problem with Deadheading Demand, Oper. Res. 61, 2, iii-529 (2013) https://doi.org/10.1287/opre.1120.1154

24. R. Martinelli, M. Poggi, A. Subramanian, Improved bounds for large scale capacitated arc routing problem, Comp. \& Oper. Res, 40, 8, 2145-2160 (2013) https://doi.org/10.1016/j.cor.2013.02.013

25. Hertz, A., G. Laporte, M. Mittaz, A tabu search heuristic for the capacitated arc routing problem, Oper. Res, 48, 1, 1-188 (2000) https://doi.org/10.1287/opre.48.1.129.12455

26. J. Brandão, R. Eglese, A deterministic tabu search algorithm for the capacitated arc routing problem, Comp. \& Oper. Res, 35, 4, 1112-1126 (2008) , https://doi.org/10.1016/j.cor.2006.07.007

27. E.B. Tirkolaee, M. Alinaghian, M. Bakhshi Sasi, M.M. Seyyed Esfahani, Solving a robust capacitated arc routing problem using a hybrid simulated annealing algorithm: a waste collection application, J. of Ind. Eng. and Manag. St. 3, 1, 61-76 (2016)

28. E.B. Tirkolaee, I. Mahdavi, M.M.S Esfahani, A Robust Periodic Capacitated Arc Routing Problem For Urban Waste Collection Considering Drivers And Crew's Working Time, Wast. Man. 76, 138-146 (2018) https://doi.org/10.1016/j.wasman.2018.03.015

29. E.B. Tirkolaee , P. Abbasian, M. Soltani, S.A Ghaffarian, Developing an applied algorithm for multi-trip vehicle routing problem with time windows, urban waste collection: A case study, J. Sust. Circ. Eco. 37, 14-13 (2019) https://doi.org/10.1177/0734242X18807001

30. P. Lacomme, C. Prins, W. Ramdane-Chérif, A Genetic Algorithm for the Capacitated Arc Routing Problem and Its Extensions, Boers E.J.W. (eds) Applications of Evolutionary Computing, EvoWork. 2037 (2001) https://doi.org/10.1007/3-540-45365249

31. Wahiba Ramdane-Cherif, Problèmes d'optimisation en tournées sur arcs"' (2002)

32. R.K. Arakaki, F.L. Usberti, Hybrid genetic algorithm for the open capacitated arc routing problem, Comp. \& Oper. Res, 90, 221-231 (2018) https://doi.org/10.1016/j.cor.2017.09.020

33. P. Lacomme, C. Prins, A. Tanguy, Optimisation par colonies de fourmis pour les tournées sur arcs (2003).

34. A. Kansou, A. Yassine, Ant Colony System for the Periodic Capacitated Arc Routing Problem, Inter.l Net. Opt. (2009) 
35. L. Santos, J.C. Rodrigues, J.R. Current, An improved ant colony optimization based algorithm for the capacitated arc routing problem, Transp. Res. P B: Meth. 44, 2, 246266 (2010) https://doi.org/10.1016/j.trb.2009.07.004

36. Y. Chen, P. Rohlfshagen, L. Xing and X. Yao, A Hybrid Ant Colony Optimization Algorithm for the Extended Capacitated Arc Routing Problem, IEEE Transactions on Systems, Man, and Cybernetics, Part B (Cybernetics), 41, 4, 1110-1123, (2011), https://doi: 10.1109/TSMCB.2011.2107899

37. J. Boukachour, B. Dkhissi, AEH. Alaoui, T. Lamoudan, Un algorithme hybride pour la résolution du problème de collecte des déchets (2012)

38. EB Tirkolaee, M Alinaghian, AAR Hosseinabadi, M B Sasi, A K Sangaiah, An improved ant colony optimization for the multi-trip Capacitated Arc Routing Problem, $\begin{array}{llllll}\text { Comp. } \quad \& \quad \text { Ele. } & \text { Eng, } & \text { 77, } & 457-470 & \text { (2019) }\end{array}$ https://doi.org/10.1016/j.compeleceng.2018.01.040

39. P. Lacomme, C. Prins, W.R. Cherif, Evolutionary algorithms for periodic arc routing problems, Euro. J. of Oper. Res, 165, 2, 535-553 (2005) https://doi.org/10.1016/j.ejor.2004.04.021

40. F. Chu, N. Labadi, C. Prins, Lower bounds for the Periodic Capacitated Arc Routing Problem (2003)

41. F. Chu, N. Labadi, C. Prins, Heuristics for the periodic capacitated arc routing problem, J. Intell. Manuf, 16, 2, 243-251 (2005). https://doi.org/10.1007/s10845-004$\underline{5892-8}$

42. F. Chu, N. Labadi, C. Prins, A Scatter Search for the Periodic Capacitated Arc Routing Problem, Euro. J. of Oper. Res, 169, 2, 586-605 (2006). https://doi.org/10.1016/j.ejor.2004.08.017,

43. Y. Mei, K.Tang, X.Yao, A Memetic Algorithm for Periodic Capacitated Arc Routing Problem, IEEE Transactions on Syst. Man. Cyb. 41, 6, 1654-1667 (2011), https://doi:10.1109/TSMCB.2011.2158307.

44. Y. Zhang, Y. Mei, k. Tang, K. Jiang, Memetic algorithm with route decomposing for periodic capacitated arc routing problem, Ap. Soft Comp. 52, 1130-1142 (2017). https://doi.org/10.1016/j.asoc.2016.09.017

45. Y. Chen, J.K. Hao, Two phased hybrid local search for the periodic capacitated arc routing problem, Euro. J. of Oper. Res, 264, 1, 55-65 (2018) https://doi.org/10.1016/j.ejor.2017.06.025

46. E.B. Tirkolaee, A. Goli, M. Pahlevan, R.M. Kordestanizadeh, A robust bi-objective multi-trip periodic capacitated arc routing problem for urban waste, Wast. Manag. \& Res, 37, 11, 1089-1101 (2019) https://doi.org/10.1177/0734242X19865340

47. B. Kanso, Hybrid Ant Colony Algorithm for the Multi-depot Periodic Open Capacitated Arc Routing Problem, Inter. J. of Arti. Intel. \& Ap, 11 DOI:10.5121/ijaia.2020.11105

48. T. Stutzel , H.H. Hoose, Gener Comput Syst, 16, 8, 889-914 (2000) 